
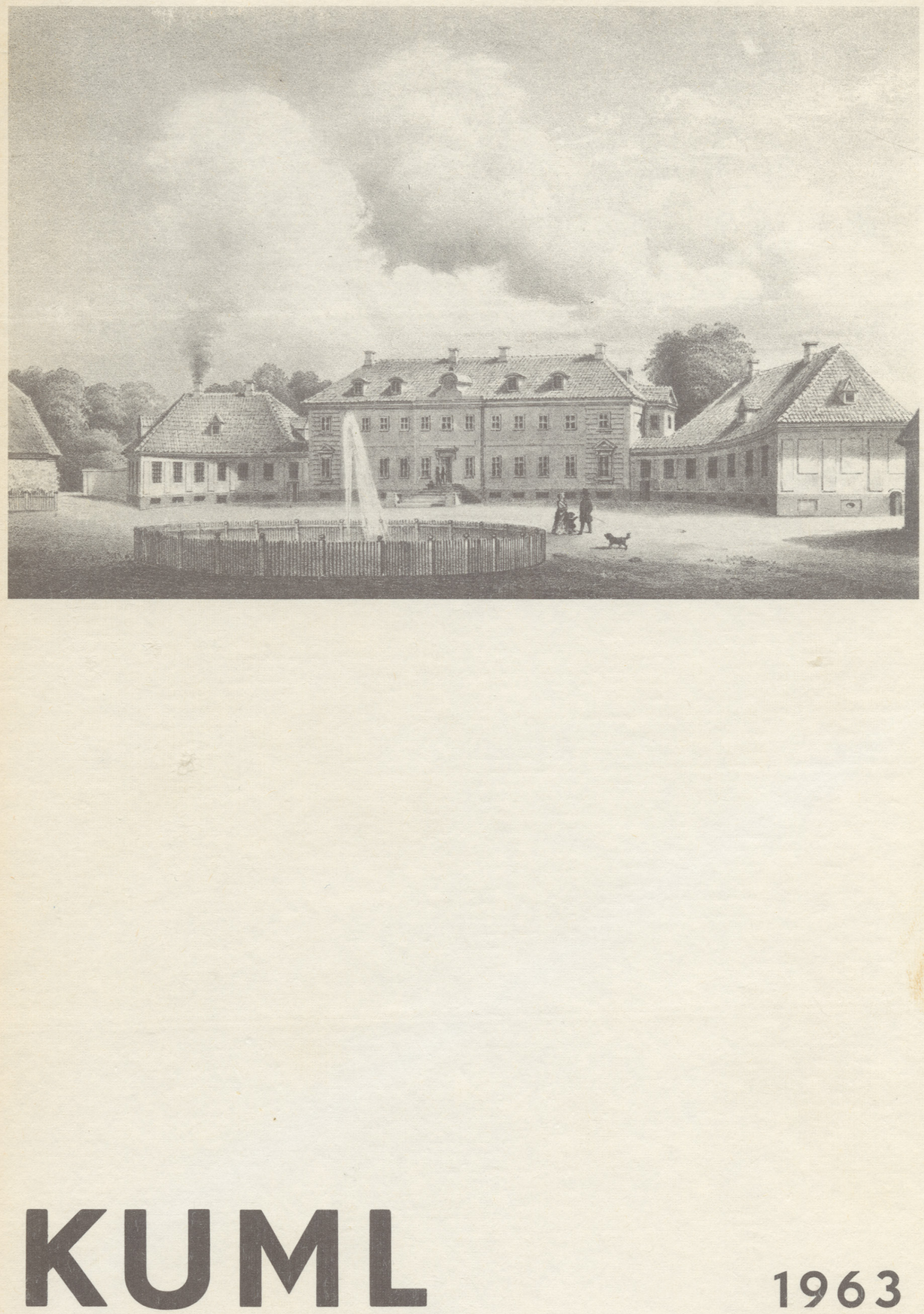

1963 


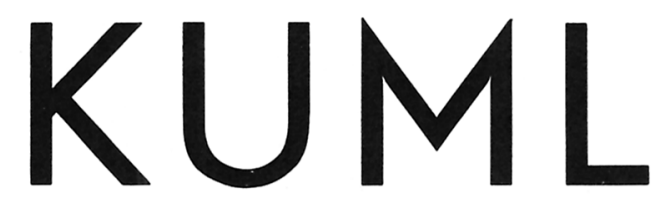

\section{ÅRBOG FOR JYSK ARKÆOLOGISK SELSKAB 1963}

With Summaries in English 
Omslag:

MOESGÅRD

F. RICHARDT del.

Redaktion:

OLE KLINDT-JENSEN OG POUL KJÆRUM

Copyright 1964

by

Jysk Arkcoologisk Selskab

Printed in Denmark

by

Aarhuus Stiftsbogtrykkerie A/S 


\section{IN D H OLD}

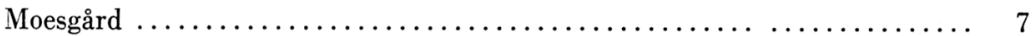

Ebbe Lomborg: Gravfund fra Stubberup, Lolland ................. 14

Menneskeofringer og kannibalisme i bronzealderen.

Oscar Marseen: Lundegårde-gravpladsen fra yngre jernalder ........... 33

Erik Moltke: Runeindskriften på rosetfibulen fra Nøvling ........... 37

Palle Friis: Jernaldergrave ved Gjurup med teltformede d $\phi$ dehuse ....... 42

Robert Thomsen: Forsøg på rekonstruktion af en fortidig jernudvindings-

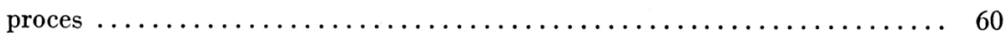

Ole Klindt-Jensen og Hellmuth Andersen: Det ældste Århus ........... 75

Margrethe Hald: Vævning over gruber ...................... 88

Klaus Ferdinand: Nomadisme ........................... 108

Jysk Arkæologisk Selskab ............................... 148

\section{CONTENTS}

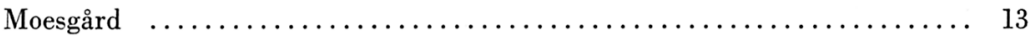

Ebbe Lomborg: A grave from Stubberup on Lolland-Human sacrifice and

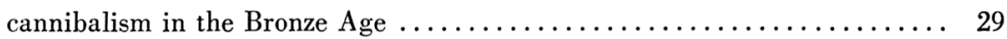

Oscar Marseen: The Lundegårde cemetery from the Late Roman Iron Age.. 36

Erik Moltke: The runic inscription on the rosette fibula from N $\varnothing$ vling .... 40

Palle Friis: Iron Age graves at Gjurup with tent-shaped grave-houses ..... 57

Robert Thomsen: Trial reconstruction of an early process of iron extraction 70

Ole Klindt-Jensen og Hellmuth Andersen: Oldest Århus ............. 85

Margrethe Hald: Pits, looms and loompits ...................... 104

Klaus Ferdinand: Nomads $\ldots \ldots \ldots \ldots \ldots \ldots \ldots \ldots \ldots \ldots \ldots \ldots, 140$ 


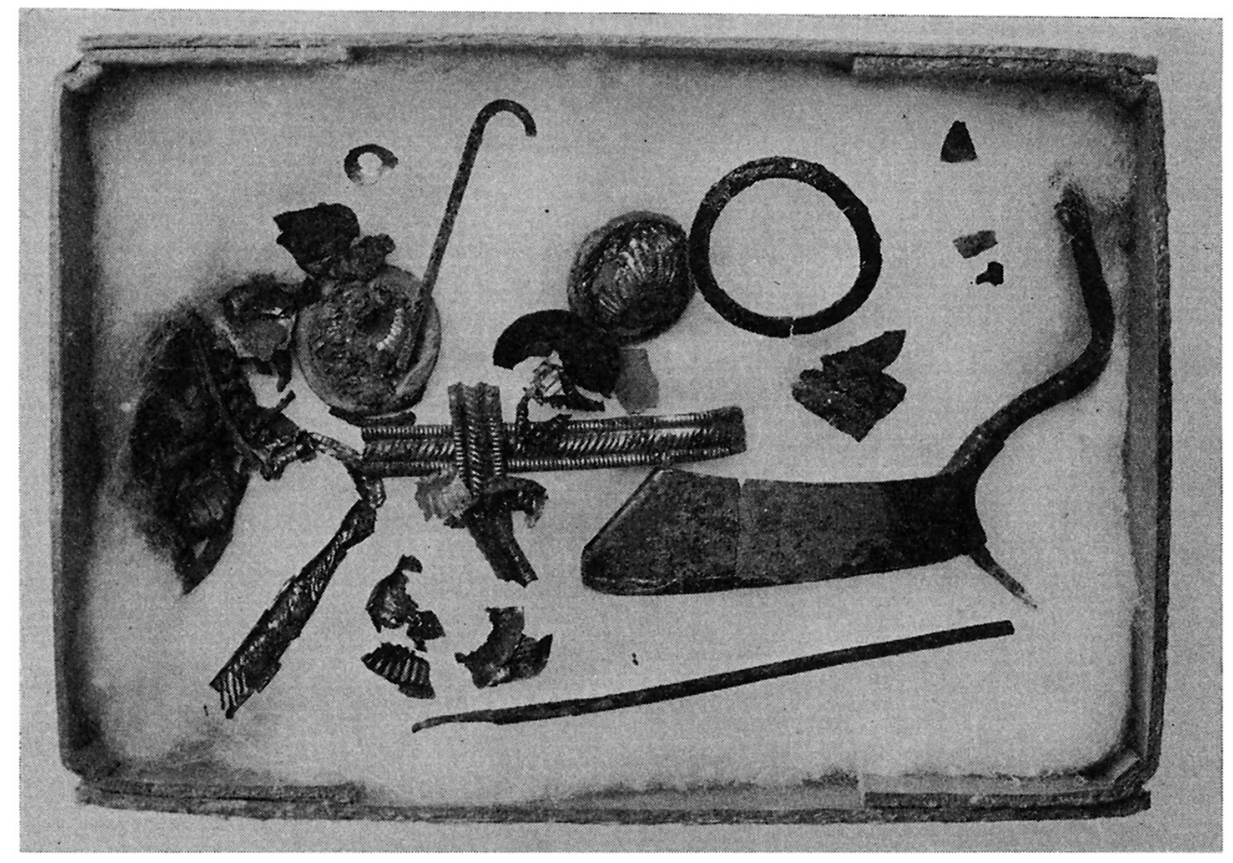

Fig. 1. En æske runefibula.

A box of rune-bearing fibula.

\title{
RUNEINDSKRIFTEN PÅ ROSETFIBULEN FRA NØVLING
}

\author{
Af ERIK MOLTKE
}

Siden udgivelsen af "Danmarks runeindskrifter " 1942 er der fundet omkring en halv snes genstande med indskrifter ristet i det ældste runealfabet, 24-tegnsfutharken, der anvendtes fra runernes opfindelse omkr. eller noget efter vor tidsregnings begyndelse og til ca. 6-800, da den sprængtes og gav plads for den ejendommelige 16-tegns-futhark, hvormed vore stenindskrifter er ristede. Denne havde den ejendommelighed, at den var lettere at riste end at læse.

De sidste to urnordiske indskrifter fremkom 1963, først på en »kødkniv « eller skindskraber fra Fælleseje, Slemminge sogn, Lolland (Slemminge skindskraber ${ }^{1}$ )) med indskriften witrng, d. e. witring, ejendommelig ved sin endelsesløse form, dernæst den indskrift, vi her skal opholde os lidt ved, ristet på en meget søndret pragtfibula (fig. 1), ret beset en noget barbarisk prydgenstand, med store, iøjnefaldende rosetter. Dens navn bliver derfor - eftersom runeværket betegner genstandene ved sognenavn - Nøvling-rosetfibulen. Angående de nærmere omstændigheder vedrørende findested og fibulens arkæologiske placering $\mathrm{m}$. v. se foran p. $33 \mathrm{ff}$. 
Det er pudsigt, at det er rosetfibuler af samme type som den her omhandlede, der udg $\varnothing \mathrm{r}$ hovedparten af de sidst fremkomne genstande med urnordiske runer, nemlig to sjællandske, Værløse (a lu god), Himling $\varnothing j e$ ( ...widuhudaz), en jysk, Næsbjerg (w a r a f n i s(a)) samt en skånsk, Gårdlösa (e k u n w o d?) og nu atter en jysk, hvor der synes at stå

$$
\text { bidawarijaz talgidai } i^{2} \text {. }
$$

Lad os først se på indskriftens læsning. Runerne er, som det fremgår af afbildningen fig. 2 skarpt og sikkert graveret eller ridset med meget fine, ikke særlig dybtgående streger ned i sølvet på nåleskedens udside - samme plads som indskrifterne på de øvrige rosetfibuler indtager. Den har følgende udseende:

\section{BIDRPRRIDRY个RTXIX(RI)}

Bortset fra de to sidste tegn giver ingen af de andre runeformer anledning til kommentarer. De er alle normaltyper af den art, der brugtes fra runealfabetets opståen og til dets undergang. Læsningen bliver da:

$$
\text { bidawarijaz talgid (ai) }
$$

de sidste to runer sætter vi foreløbig i parentes; det vil nedenfor fremgå, hvorfor. Men foreløbig læser vi indskriftens første del som mandsnavnet bi d a w a ri j a $\mathrm{z}$, det andet som et verbum i datid 3die person ental, det endnu i jysk brugte ord »tælle«, ældre telgja, snitte. Men endelsen er mærkelig; der skulde ikke stå t a l gidai, men talgide. Har vi at gøre med en eller anden førkristelig form, der gør indskriften ældre end fibulen? har vi at gøre med arkaiserende sprog? eller lever denne verbalendelse endnu i 3. århundrede? etc., etc., som alle de gamle - og en hel del nulevende - sprogfolk vilde spørge. Vi gemmer dette h $\varnothing$ jst interessante spørgsmål til lidt senere og siger først et par ord om mandsnavnet. Slutleddet -warijaz (oprindelig: som værner) der bliver til -warijaR, og atter til vér og til er, ir, er velkendt; det er bl. a. overleveret på en norsk runesten fra urnordisk tid i navnet $\mathrm{l}$ ad a warijaz, der efter en almindelig ortografisk runeregel skal læses Landawarijaz, som atter vilde svare til en moderne form Land $(v) e r$. Fra danske runestene kender vi navneleddet på Vordingborg-stenen, hvor der vistnok skal læses p i a u p u ir (Danmarks runeindskrifter nr. 221), og man antager, at det samme led går igen i navne som Guthir, Roar, Roir, Stener, Swerker, Thorir etc. Selve sammensætningen bid a w a rij a z kendes ikke, hvad enten man læser navnet som Bídawarijaz, Büdawarijaz eller Bindawarijaz, altså svarende til moderne former som Bid-, Bed-, Bind(v)er. Under disse omstændigheder er det ret $\emptyset$ rkesl $\emptyset$ st at g $\varnothing$ re fors $\varnothing \mathrm{g}$ på at fastslå netop den bestemte navneform, vor mand har båret. Vi kan nøjes med at konstatere, at hans navn er sammensat af velbekendte led (nemlig med relation til verberne bíða (vente), biðja (bede), binda (binde)). Vi vil derfor for nemheds skyld, men højst uvidenskabeligt, kalde ham for Bedver. Uanset om vi her har truffet det rette, er det urnordiske navneforråd imidlertid blevet for $\varnothing$ get med endnu et egennavn af normal type.

Mens mandsnavnet, rent sprogligt, næppe åbner videre perspektiver, er det anderledes med verbet, der både ved sin ristede form og i kraft af sin betydning 


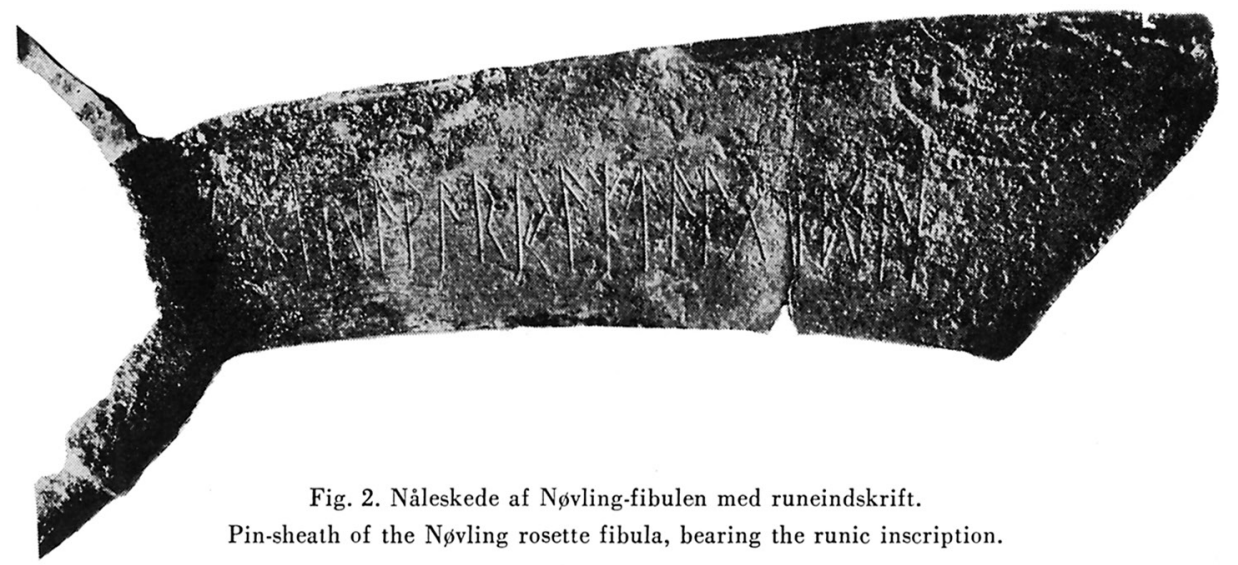

giver anledning til frugtbare tanker, tanker, der længe har groet på forfatterens ager, og som nu ved dette får tilført ny kraft.

Først bemærker man, at alle indskriftens runer - som ovenfor bemærket står skarpt og sikkert ristede UNDTAGEN de to sidste a i. I alle de forudgående er der ingen vaklen. Og så skal det netop være de "vaklende", der sprogligt gør knuder.

\section{Man venter formen $P$ P $P$ XIMM \\ t a $l$ g i d e \\ Man har fået \\ 个F个XIXRI}

Men lad os lægge mærke til, at a-runen er ganske unormal, med en alt for lang $\emptyset$ vre bistav, og i-runen bryder ganske den smukt holdte runeh $\varnothing$ jde - den virker mere som en afsluttende rammestreg end som en i-rune.

Jeg tillader mig i denne forbindelse at citere fra min ovenfor omtalte artikel: "Er runeskriften opstået i Danmark? ", hvad jeg siger om den defekte indskrift på Himling $\varnothing j$-fibulen (p. 46) : "[Foran navnet wi d u h u d a $z=$ Widuhundaz er der] plads til 7-8 runer, og man gætter naturligvis straks på de to fra indskriftforrådet velkendte verber: $\mathrm{taw}$ ide (gjorde), hvorved Vedhund bliver navnet på selve guldsmeden, eller på f a ihide (malede, skrev), der da fortæller, ikke, at det var Vedhund, der ristede runer på fibulaen, men at det var den runekyndige (nemlig Vedhund), der komponerede indskriften som forskrift for den ikke runekyndige guldsmed (hvis navn vi i så tilfælde ikke får at vide) «. Her kommer Nøvling-fibulen med den naturligste løsning og - et nyt verbum: telgja (snitte). Det siger, at mester Bedver ikke er navnet på den guldsmed, der lavede fibulen, men derimod på den runemester, der komponerede indskriften som forskrift for den ikke runekyndige guldsmed (hvis navn vi ikke får at vide), indsnittede den for ham $\mathrm{i}$ træ, runernes oprindelige materiale. $\mathrm{Og}$ så er det let at forstå, hvad der er sket: enten har runemester Bedver snittet den sidste rune lidt utydeligt, eller også har guldsmeden mistet lidt af sin opmærksomhed; resultatet er, at runemesterens 
M (e) blev misforstået til ₹ I(a i). Så simpelt er det. Guldbrakteaternes indskrifter med de ældre runer ( ja, også de latinske indskrifter med latinske bogstaver for den sags skyld) og Sven Estridsens runemønter giver exempler i massevis på tilsvarende og meget værre misforståelser. Så begriber vi også, at det er formålsløst at spilde alt for megen tid på en rekonstruktion af den i фvrigt meget sjuskede indskrift på det skånske rosetspænde (Gårdlösa-fibulen), en ufuldstændig og fordærvet indskrift

\section{$M<\Lambda+P \& A r$}

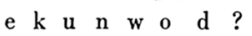

Af en sikkert fejlfri forskrift, hvis runemester betegner sig: Jeg Unwod ... er end ikke mesternavnet blevet korrekt ristet: endelsen er dels misforstået, dels udeladt. Og til verbet er der ikke blevet plads. Med Nøvling-fibulens indskrift in mente, forsigtigt jævnført med Himlingøje og Næsbjerg, tør vi dog slutte, at også Gårdlösa har indeholdt en runemesterformel: Jeg U. skrev, snittede, malede ell. lign.

Nøvling-fibulens indskrift kræver også de af andre og mig selv fremsatte tolkninger af Værløse-fibulens a lu god taget op til fornyet overvejelse. Antagelsen af et ufuldstændigt kvindenavn Alugod [o] eller et navn i tiltaleform (uden endelse) forekommer på baggrund af Nøvling-fibulen mindre sandsynlig. Her kan f. eks. være tale om en indskrift, der indledes med det velkendte værneord al u og fortsættes med et runemesternavn, der begynder med Goð-, de eneste runer, guldsmeden fik plads til på det begrænsede rum foran det allerede indristede hagekors, eller om et runemesternavn, der begynder med Alugod ... Ingen ved det - endnu.

\section{The runic inscription on the rosette fibula from $N \phi v l i n g$}

The inscription on the rosette fibula from Nøvling is written in the earlier runic alphabet, the futhark of 24 signs, which was used from the time of the invention of runes about, or shortly after, the beginning of the Christian Era until about 6-800 A.D.

It reads bidawarijaz talgid (ai), all the runes being clearcut and of even height except the last two, where the upper oblique stroke of the $a$ is unduly long and the $i$ unduly tall.

Bidawarijaz is an otherwice unknown man's name of quite normal form; the end component-wari ja z having the meaning of "ward" or "protector", while b i d a-may be derived from biðda (to wait), biðja (to pray) or binda (to bind).

$\mathrm{T}$ alg id (a i) is 3rd person singular past tense of the verb telgja, to carve (in wood), but the form to be expected is $\mathrm{tal} \mathrm{gid}$. There is no need to postulate an archaeism or a dialect survival of a pre-Christian verbal ending. It is clear that Bedver (as we may unscientifically call him) was the rune-master who cut on a piece of wood the inscription which the goldsmith copied on the fibula. He may have cut the final $e(M)$ of t a lgide somewhat carelessly; in any case the goldsmith copied it incorrectly as a i $(\mathbf{R} \mid)$.

Erik Moltke, Nationalmuseet, København. 


\section{NOT E R}

1) Publiceret af Kjeld Snedker i Maribo M. 2) Jeg har behandlet de næunte indskrifter (bortset fra den skånske) i Nationalmuseets Arbejdsmark 1951, p. 47 ff. »Er runeskriften opstået i Danmark? « Her er Næsbjerg-indskriften læst: w a r a f a u s a, idet jeg opfattede det bagvendte a (foran $u$ ) som en binderune sammen med u. Carl J. S. Marstrander har imidlertid med uomstødeligt fotomateriale vist, at denne rune ikke er a, men n, idet tværstregen gennemskærer hovedstaven. Derimod kan jeg ikke f $\varnothing$ lge Marstrander, når han vil læse Næsbjergindskriften fra venstre til højre, idet både w- og r-runerne utvetydigt viser, at her er tale om en indskrift med venderuner, der skal læses fra højre mod venstre; hertil kommer, at den læsning, Marstrander således fär frem, er noget ejendommelig, jfr. i $\phi v r i g t$ hans skrift »De nordiske runeinnskrifter i eldre alfabet. Særtryk af Viking 1952 p. 85 ff. Læsningen af Næsbjerg-indskriften må derfor være wa raf $\mathrm{n}$ is (a), idet man ikke på palæografisk grundlag kan afgøre, om sidste rune er a eller i. Her er sikkert tale om et mandsnavn, hvis første led er det velkendte (oldnordisk) varr, som varer sig, inden han foretager sig et eller andet - jfr. i jysk det tilsvarende verbum: $a$ wår mi mund, der oftest siges, når en eller anden har fortalt noget rigtig ondskabsfuldt om en anden -, mens andet led har tilknytning til verbet fnise, oldnord. fnísa, egentlig puste luft ud gennem næsen, idet man småler eller, som man også vilde sige på jysk, flirer. Tilnavnet Fliri er i øvrigt bekendt; han har været Varfnis's modsætning. 